\title{
Kernos
}

Revue internationale et pluridisciplinaire de religion grecque antique

5 | 1992

Varia

\section{Greg R. STANTON, Athenian Politics c. $800-500$ B.C. A Source Book}

\section{loannis Loucas}

\section{OpenEdition \\ Journals}

\section{Édition électronique}

URL : http://journals.openedition.org/kernos/1079

DOI : 10.4000/kernos. 1079

ISSN : 2034-7871

\section{Éditeur}

Centre international d'étude de la religion grecque antique

\section{Édition imprimée}

Date de publication : 1 janvier 1992

ISSN : 0776-3824

\section{Référence électronique}

Ioannis Loucas, "Greg R. stanton, Athenian Politics c. 800-500 B.C. A Source Book », Kernos [En ligne], 5 | 1992, mis en ligne le 20 avril 2011, consulté le 24 septembre 2020. URL : http:// journals.openedition.org/kernos/1079; DOI : https://doi.org/10.4000/kernos.1079 
l'attaque de Sextus Empiricus contre la théologie dogmatique, et traite avec beaucoup de finesse des problèmes concernant la pensée théologique de Plotin.

Le livre comporte une bibliographie (p. 311-324), un index général (p. 325-332), ainsi qu'un index des textes cités (p. 333-340).

Éveline LOUCAS-DURIE (Athènes)

Pierre HADOT, Plotin. Traité 50 (III, 5). Introduction, traduction, commentaire et notes, Paris, Éd. du Cerf, 1990, 1 vol. 12,5 x 19,5 cm, 291 p. (Coll. Les écrits de Plotin publiés dans l'ordre chronologique sous la direction de Pierre Hadot). ISBN : 2-204-04135-1. Prix : 140 FF.

Cet ouvrage est le deuxième d'une collection qui s'attache à fournir au public une traduction des œuvres de Plotin (cf. Kernos, 1 [1988], p. 253, pour le compte rendu du premier volume). Le traité 50 du philosophe pose la question de savoir si l'Amour - Éros - est un Dieu, un démon ou un état de l'âme. Partant des mythes du Banquet de Platon concernant les deux Aphrodites et la naissance d'Éros, de même que de considérations du Phèdre, Plotin propose un exercice d'exégèse allégorique qui lui permet «d'amener l'âme à découvrir que ce qui fait naître en elle l'Amour, c'est à la fois la présence et l'absence du bien en elle» (p. 21).

Pour l'historien de la religion grecque, cette œuvre est une illustration intéressante de l'utilisation de mythes parmi les plus anciens et les plus connus des Grecs par une pensée philosophique qui y décèle un certain nombre de réalités métaphysiques qu'il s'agit de traduire. Dans le cas présent du thème de la double Aphrodite, "ouranienne» et "pandémienne», P. Hadot a également montré, dans un bref appendice, l'influence du traité 50 de Plotin sur la pensée et l'art de la Renaissance. Ainsi voit-on Botticelli et le Titien, puisant aux sources antiques par l'intermédiaire de Marsile Ficin et de Pic de la Mirandole, offrir l'image d'une "Vénus" dont la conception se trouve davantage chez Plotin que dans la Théogonie hésiodique.

Soulignons enfin que ce petit ouvrage est remarquablement écrit et que la traduction élégante du traité en rend l'abord très agréable.

\section{Vinciane PIRENNE-DELFORGE (Liège)}

Greg R. STANTON, Athenian Politics c. 800-500 B.C. A Source Book, London-New York, Routledge, 1990, 1 vol. 13,5 x 21,5 cm, 226 p.

Le développement politique et l'évolution sociale de la démocratie athénienne pendant la période archaïque sont le sujet de cet ouvrage. L'«Attique d'avant Solon», «Solon», «De Solon à Pisistrate», «la tyran- 
nie des Pisistratides" et "Clisthène" constituent les cinq parties examinant l'histoire athénienne et sont suivies d'une sixième qui, elle, présente un grand intérêt notamment pour les historiens de la religion : "Les familles nobles» (p. 191-209). Cette partie réunit les sources anciennes (littéraires et épigraphiques) les plus importantes pour déterminer le rôle, dans la vie sociale, politique et religieuse d'Athènes, des puissants clans familiaux. Les Philaidai et les Alkmeonidai y occupent la plus grande place (p. 195-206), cependant que l'on notera avec regret - l'absence de clans aussi importants que les Kerykai, les Lykomidai, etc. L'ouvrage s'achève par de brèves notices sur les auteurs anciens dont il a été question (p. 210-211), un index des sources littéraires et épigraphiques traduites (p. 212-215), et un index des noms et des sujets (p. 216-226).

Ioannis LOUCAS

Jean WINAND, Les Hiérothytes. Recherche institutionnelle, Bruxelles, Palais des Académies, 1990, 1 vol. 16 x 23,5 cm, 230 p. (Académie Royale de Belgique. Mémoires de la Classe des Lettres. Coll. in $-8^{\circ}-2 e$ série, $T$. LXVIII - Fascicule 4).

On connaît la place prépondérante qu'occupait le sacrifice dans la religion grecque et l'on sait quel prestige était dévolu par la cité aux desservants du culte chargés d'en assurer le bon déroulement. Attestée presque exclusivement pär des inscriptions, la fonction de hiérothyte est mal connue tant sa nature apparaît différente selon les régions et les époques. Seule une étude reprenant le dossier $a b$ ovo pouvait contribuer à mieux faire connaître cette fonction religieuse. Après avoir étudié l'évolution sémantique de la terminologie s'y rapportant, J. Winand constitue le dossier épigraphique en suivant un plan géographique : Rhodes, le Péloponnèse, Cyrène, la Sicile, voilà les principales étapes de son enquête. Grâce à ce corpus qui compte environ 130 inscriptions, il parvient à établir plusieurs conclusions éclairantes, malgré le caractère répétitif et formulaire de la plupart des textes étudiés.

Attestés seulement à partir de la fin du Ve siècle, les hiérothytes occupent une fonction institutionnelle bien définie, dont l'origine remonte très probablement plus haut que les textes qui attestent son existence. Institution propre aux peuples du nord-ouest de la Grèce et aux Doriens, cette fonction semble avoir connu une fortune diverse selon les cités où elle fut en usage. Ici, les hiérothytes sont des personnages de rang subalterne, groupés au sein d'un collège, desservants du culte de divinités trop secondaires pour que la cité leur attribue un personnel propre. Là, en revanche, ces ministres du culte apparaissent comme des personnalités de premier rang, attachés au culte d'une grande divinité, le plus souvent la divinité tutélaire de la cité. Cette double nature de la 